\title{
Magazine section
}

\section{Snapshots}

\section{Congress gleanings}

\section{World Health Summit 2012}

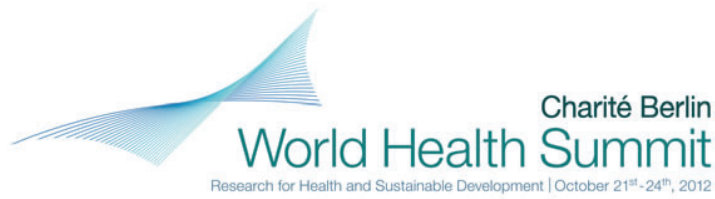

From 21st-24th October the "World Health Summit 2012" took place in Berlin and some 1200 participants from around 80 countries converged on the historic campus of the Charité-Universitätsmedizin Berlin to experience 278 speakers in over 50 sessions.

"Research for Health and Sustainable Development" was the theme of the meeting, articulating the urgent need to find novel solutions for non-communicable diseases and conditions of global concern, such as obesity, diabetes, and mental illness. Unhealthy lifestyles, including smoking, alcohol and nutrition, are a main cause of these epidemics in both rich and poor, developed and developing countries. Hence, central demands are:

- Greater awareness and efficient programs are urgently needed to face the caused global economic risks and human suffering.

- Improvement of the epidemiologic demographic transition is mandatory.

- Sustainable solutions must be found for healthcare systems.

- Research capacity strengthening in low and middle income countries is advocated as a prerequisite for improving health.

- The transformation of the existing "sick care systems" into "health care systems" with an emphasis on prevention must be achieved.

Governments around the world are facing increasing financial constraints, and the challenge to provide quality healthcare is an increasing struggle. The economic crises affecting many nations and regions pose many challenges, but also represent an opportunity to reform health systems and to rethink the direction and nature of financing for research and health, resulting in more money for health and more health for the money.
Science must be sensitive to financial realities, so that scarcity of resources will be considered an enabler of - not an impediment to - sustainable innovation. Maximizing the benefits from limited resources ensures that the gains of medical progress reach as many people as possible. Important topics that need to be discussed are priorities for research, public and private sector partnerships, intellectual property rights, regulatory procedures for health products, conventions on biomedical research and development, and the place of information technology in health care systems.

Accordingly, the "World Health Summit 2012" was organized into five program tracks:

1. Diseases of modern environments

2. Translating research into policy

3. Health and economy

4. Educating health professionals

5. Information technology for health.

In 2013, two meetings will take place: the World Health Summit Regional Meeting in Singapore, 8th-10th April 2013 and the 5th World Health Summit in Berlin, 20th-22nd October 2013 (source: Charité Berlin).

For more information please visit:

http: //www. worldhealthsummit.org/

(04.01.2013).

\section{Funding}

\section{Wilhelm Sander Foundation}

\section{Wilhelm Sander-Stiftung}

The Wilhelm Sander Foundation emerged from the estate of the manufacturer, Wilhelm Sander, who died in December 1973 in Neustadt an der Donau. It supports research projects in the field of human medicine with particular focus on cancer research (clinical and experimental). Research projects that are not connected to cancer issues must be about a patient-related issue.

Funding from the Wilhelm Sander Foundation is restricted to Germany and Switzerland. 
In the past 5 years the acceptance rate of funding requests has been approx. 35\%. The duration of the application process takes on average 4 to 5 months, although in some cases the processing of the application may take longer. Detailed information can be found at:

http: / / www . sanst.de

(04.01.2013).

\section{Sonnenfeld Foundation for the promotion of medical research in Berlin - New deadlines in 2013}

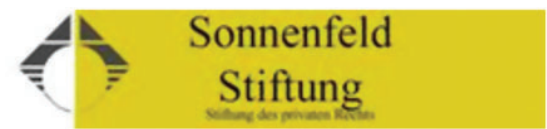

The purpose of the foundation is to promote research and the application of modern diagnostic and treatment methods used in human medicine. Within this framework, it can, for example, support the development of modern medical equipment with funds, procure equipment and provide appropriate facilities.

In detail this includes:

- $\quad$ Funding of research projects, for example providing materials or equipment, thereby acknowledging that the study of modern diagnostic and treatment methods is only possible with the help of specific basic research.

- Granting scholarships for students studying for a doctorate in a medicine related subject.

Funding is only available for projects and doctorate studies in the Berlin area.

New funding requests should be submitted in writing as one original and five copies (applications by email or fax will not be accepted) until the 21st March 2013 (date of receipt). Applications arriving after 21st March 2013 will not be processed.

Detailed information can be found at:

http: / / www. sonnenfeld-stiftung.de/

(04.01.2013)

\section{News from the industry}

\section{Michael Mertin from Jenoptik AG elected as new President of Photonics21}

Brussels, 13th November 2012. The Board of Stakeholder of the European Technology Platform Photonics21 has elected Dr. Michael Mertin, CEO of jenoptik AG, Jena, as the new President of the organization representing the European Photonics Community in the fields of optical technologies. Dr. Mertin takes over the position from departing President Martin Goetzeler of Osram AG.

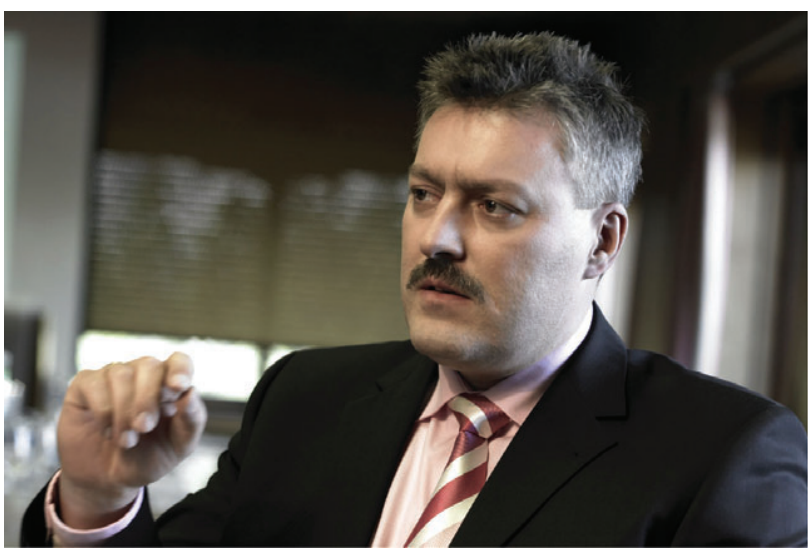

Dr. Michael Mertin, CEO of jenoptik AG, Jena (source: Photonics21).

The new President studied physics at the University of Aachen (RWTH Aachen), and gained his PhD in Engineering at the Fraunhofer Institute for Laser Technology. He will lead Photonics21 during the decisive phase when Europe's Research and Innovation policy transitions into the new European Framework Program "Horizon 2020". Photonics, having been designated as one of the EU Commission's five "Key Enabling Technologies", will play a major role in "Horizon 2020", resulting in significant industrial growth and new jobs.

In his introductory address, Dr. Mertin confirmed that Photonics21 welcomes the EU Commission's new "Horizon 2020" program with its strong emphasis on funding for innovation, and focus on achieving real impact on growth and jobs. "This implies that Europe is fully exploiting and developing those technologies, in which Europe has a strong and well-established industry base, able to gain and defend a leading competitive position".

On the subject of the role of "Horizon 2020", he continued: "Since Europe is facing an economic crisis and has been cutting budgets across the continent, it is now crucial to ensure that every euro is spent wisely, and that all stakeholders live up to their commitments and responsibilities. Photonics21 will support this endeavor through the establishment of a public-private-partnership (PPP) and an industry pledge to a four-fold leverage of public funding. This future PPP is the expression of our full commitment to pursue cooperation between private and public sectors, and the perfect instrument to strengthen Europe's innovation capacity" (source: Photonics21). 
More information about Michael Mertin and Photonics 21 can be found at

http: / / www . photonics21.org/

(04.01.2013).

\section{Instrument Systems GmbH becomes a consolidated subsidiary of Konica Minolta Optics, Inc.}

30th November 2012. With effect from 1st December 2012, the company founder and president Richard Distl, sold Instrument Systems GmbH, established in 1986, to Konica Minolta Optics, Inc. The subsidiary company Optronik Berlin $\mathrm{GmbH}$ is also included in the sale.

The Munich company, specialized in lighting measurement equipment, will expand the sensing division of the Japanese Group with its successful product range. The Instrument Systems brand and the locations in Munich and Berlin will be retained. Furthermore, the previous owner, Richard Distl, will continue as President and CEO. "The company was established 26 years ago and it has undergone enormous growth since then. The time had come to chart a strategic roadmap for the sustainable further development of the company. Konica Minolta is the right partner and offers outstanding framework conditions for development”, commented Richard Distl as he explained his decision.

Toshihiko Karasaki, President of Konica Minolta Optics, sees the acquisition of the company with a high global reputation as aligning with the Group's strategy: "Our goal is to have a leading global position in all our corporate divisions and to integrate international talent within our group. Instrument Systems is the best company in LED lighting measurement to consistently implement this strategy. Together, we now cover all segments of display and light-source measurement and we are positioned as number one in this area”. Konica Minolta Optics and Instrument Systems will cooperate closely on product development in future with the objective of further expanding this position (source: Instrument Systems). For more information please also visit:

http: / / www . instrument systems.com/ news-events/press-releases /

(04.01.2013).

\section{Siemens reduces particle therapy projects}

In 2011, the Siemens group decided not to commission the particle therapy (PT) facility at the University

Hospital Schleswig-Holstein in Kiel. The reason given by the company is the unlikelihood that the project would make a profit.

Before pulling out of the facility in Kiel, Siemens had already withdrawn from a project in July 2011 for a similar particle therapy facility in Marburg. Instead of being for patient care, the purpose of the facility was shifted to support basic and applied research. A joint press release of the Schleswig-Holstein Ministry of Science, Technology and Transport, and Siemens AG in September 2011 stated in relation to Marburg that "this technology is not currently suited for broadly applied medical care".

Particle therapy is a technology where protons or carbon ions are accelerated to very high speeds (60 to 70\% of the speed of light) and are then directed precisely at the diseased tissue. Unlike conventional radiotherapy, the protons and heavy ions bombard the target, destroying the core of the tumor cells, while the surrounding healthy tissue is spared (source: World Socialist Web Site).

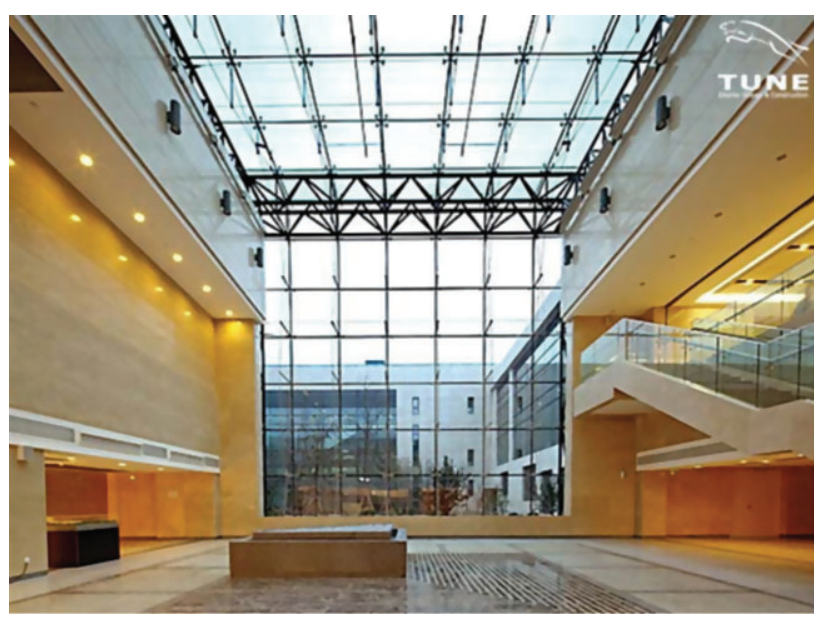

Basement of Shanghai Proton and Heavy Ion Hospital (๔ Beijing Tune Interior Design \& Construction Co., Ltd. Beijing)

The official statement on the Siemen's homepage says it "has suspended acquisition and now is concentrating on the finalization of the two PT systems under contract (Heidelberg and Shanghai)".

For more information please visit:

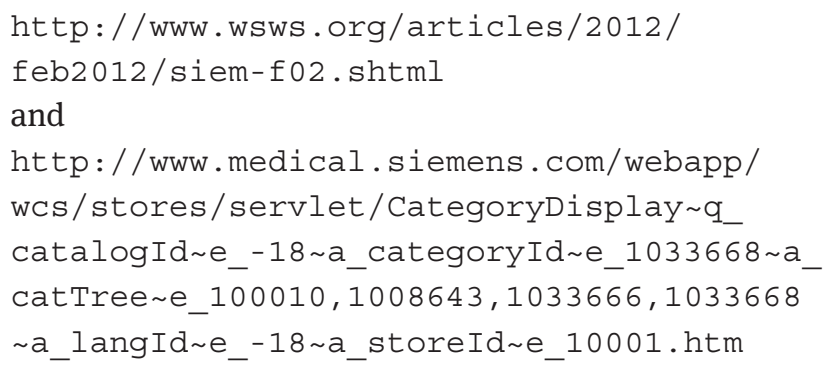




\section{Awards}

Photonics21 Student Innovation Award 2013

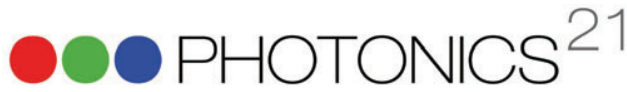

For the fifth time the European technology platform Photonics21 has announced the Photonics21 Student Innovation Award. The prize will be presented at the evening reception of the Photonics21 Annual Meeting 2013 on 29th April 2013.

The Research, Education and Training work group of Photonics21 (Work Group 7) has established a prize for students in the field of photonics in order to promote research in photonics, especially related to $R \& D$ with a significant industrial impact.

Any person under 35 and active in the field of optics and photonics may apply for the Photonics21 Student Innovation Award. The award is made up of a certificate, a trophy, as well as a cash prize of $€ 5000$.

Applicants must submit the following documents:

- A completed application form

- One letter of support (by a supervisor or mentor)

- A short (2 page) biography/CV

- A list of peer reviewed publications

- A description of the innovative $R \& D$ work (not exceeding 4 pages of A4, 12 point text), making clear the nature of innovation and the potential impact on industry.

The application deadline for participating in the Photonics21 Student Innovation Award 2013 is 20th February 2013.

Applications can be sent via e-mail to education@ photonics21.org.

See also:

http: / / www . photonics21.org/TrainingEducation/innovationaward.php

(04.01.2013).

\section{Broader view}

\section{Laser replaces injection needle}

Those who are afraid of injections may soon have grounds for hope. It may soon be possible to give injections under the skin without incurring any pain.

This is made possible by use of a special laser nozzle, developed by Korean researchers at the University of

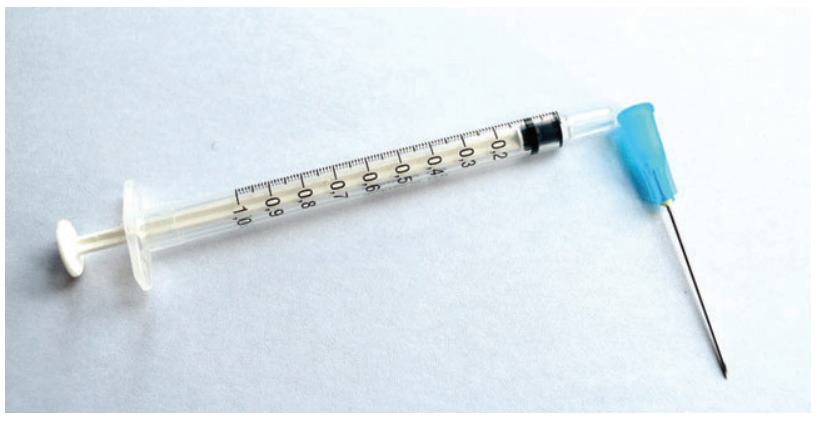

(c) PublicDomainPictures.net

Seoul. The laser nozzle injects an extremely thin liquid jet into the top layers of the skin causing the patient to experience little more than a short burst of air. Tests on guinea pigs showed that the drug can be deposited up to several millimeters deep into the skin without causing damage to the tissue. Furthermore, if one were to inject only into the upper skin layers, where no nerves run, the method would be completely painless.

Although there are other approaches to inject fluids under high pressure through the skin, these are mechanically based. The advantages of laser technology can be seen in the precise control of the dose and the depth of penetration of the active ingredients. The use of the laser needle would significantly reduce waste and would be better suited for patients with a phobia of needles (source: Wissenschaft aktuell).

See also: Park MA, Jang HJ, Sirotkin FV, Yoh JJ. Er:YAG laser pulse for small-dose splashback-free microjet transdermal drug delivery. Opt Lett 2012;37(18):3894-6.

\section{UV-C light kills bacteria in the hospital environment}

A portable device that emits UV-C light destroyed vancomycin-resistant enterococci (VRE), Acinetobacter, and Clostridium difficile from hospital rooms where patients infected with those bacteria had been housed. This is the result of a small study which was presented during a poster session at IDWeek 2012 from a team led by Dr. Deverick J. Anderson from the Department of Medicine, Division of Infectious Diseases at Duke University, Durham, NC, USA.

The team analyzed 39 rooms at two tertiary care hospitals that had just housed a patient with one of the different bad bugs: VRE, Acinetobacter, and C. difficile. After the patient was discharged but prior to the regular cleaning, the investigators obtained 15 or more cultures from several different locations in the hospital rooms, including bed 
rails, remote controls, and toilets. Then they wheeled in an automated mobile disinfection system (TRU-D, M/s Lumalier) that is about 6 feet tall and is equipped with eight sensors and 16 bulbs that emit UV-C light. Each room was irradiated then for between 25 and 45 min until a bactericidal dose was achieved $\left(\geq 12,000 \mu \mathrm{Ws} / \mathrm{cm}^{2}\right.$ for vegetative bacteria and $\geq 22,000 \mu \mathrm{Ws} / \mathrm{cm}^{2}$ for spores) in order to eradicate both bacteria and bacterial spores. After comparing the number of colony-forming units (CFUs) before and after irradiation, the UV-C irradiation reduced CFUs of VRE by $98 \%$, C. difficile by $93 \%$, and Acinetobacter by $98 \%$.
Based on these results the researchers concluded, that UV-C light is indeed effective in killing VRE, C. difficile, and Acinetobacter from the real-world hospital environment but called attention to the fact that the study was underpowered due to a low frequency of Acinetobacter infection in the study hospitals (source: Skin \& Allergy News digital network).

For more information please also see:

https: / / idsa. confex.com/idsa/2012/

webprogram/Session4 720 .html

(04.01.2013). 